\title{
South Africa 'must fight scientific illiteracy'
}

Cape Town. The Royal Society of South Africa has suggested that the government should consider some radical solutions to the problem of widespread scientific illiteracy among schoolchildren and adults including for the first time the introduction in schools of courses in evolutionary theory.

It has also suggested that the country consider increasing its efforts in taxonomy. And that one of its top scientific priorities should be the construction of a new optical telescope - although achieving this will depend on finding international partners.

The suggested priorities are contained in a discussion document on science research policy in South Africa. Apparently timed to influence policy decisions by the new government, the document provides a detailed analysis of the nation's strengths and weaknesses in all fields of science, and the related issue of science education.

The document itself has been drawn up by various members of the society. For example, the president of the society, George Ellis, suggests that schools become involved in advancing science through environmental monitoring efforts, weather observations, accumulating population census data and biodiversity atlas projects.

Two educational projects, aimed at providing comprehensive locality records of birds and the country's spectacular Protea flora, have already proved enormously successful in enlisting the help of amateurs.
The document also suggests significant changes in school syllabi, in fields such as mathematics and biology. For example, it specifically recommends placing emphasis on the importance of the theory of evolution in biology, which is currently excluded from syllabi in South Africa. Partly as a consequence of this, biology, despite an abundance of factual material, has suffered from rote-dominated teaching.

Taxonomists are likely to welcome a recommendation in another chapter of the document for the creation of a programme designed to speed up the rate of progress in taxonomy - particularly in botany — to take account of South Africa's unique diversity of species.

This recommendation may be adopted by the new government, which is keen to establish a 'green' image. In doing so, for example, it would honour the country's commitment, made in line with the declaration signed at the Earth Summit in Rio de Janeiro in 1992, to draw up an inventory of its biota.

In terms of international science, one chapter in the report points out that the country's location and climatic conditions makes astronomy an important field to develop. Top priority, it says, would be the acquisition of a new 3.5-4-metre telescope, to replace the existing one at the Astronomical Observatory at Sutherland, about $400 \mathrm{~km}$ north-east of Cape Town.

This is unlikely to take place without

\section{Museum seeks $£ 2 m$ for Darwin's home}

London. Britain's

Natural History Museum is seeking to raise $£ 2$ million to restore and develop Down House in Kent (right), home to Charles Darwin for 40 years and the place where he wrote a dozen books, including On the Origin of Species.

The museum

bought a 99-year lease on the 20-room house early last year from the Royal College of Surgeons, which itself had bought it from the British Association for the Advancement of Science in 1952. Although some of the rooms are currently open to the public, at present only 6,000 visitors make the trip to the site, 15 miles south of London, each year.

Around $£ 500,000$ is needed for urgent repairs and restoration of the building, and a similar sum for longer-term improvements. The museum's lease includes the gardens,

foreign assistance. The German government has expressed some interest in erecting a telescope in the Gamsberg mountains in Namibia, and it is also being seen as a possible alternative site for the European Southern Observatory's Very Large Telescope, currently being built in Chile (see Nature 368, 676; 1994). But this would involve the duplication of infrastructure that is already in place at Sutherland.

Another controversial aspect of the report is its section on the National Accelerator Centre (NAC), currently run on funds separately earmarked by cabinet (see $\mathrm{Na}$ ture 365, 766; 1993). The Royal Society document recommends that the future of the centre be reviewed by a specialist committee. But it is sceptical of the prospects of obtaining non-governmental funds to operate its cyclotron.

The document describes it as a "cause for concern" that the "powerful phalanx of theoretical nuclear physicists in South Africa has not enthusiastically devoted any significant portion of its attention to research in physics accessible to experimentalists using the NAC cyclotron".

It also questions whether NAC's activities justify a staff of 228 , but emphasizes that the centre's R35 million (US\$10 million) budget is negligible compared to that of the Atomic Energy Corporation - whose subsidy has, surprisingly, been increased by the new government, to R509 million.

The document's comments have already had an impact in political circles. Last week, during a debate on science in the new South African Parliament, at least one member referred to the criticisms it makes of the NAC to suggest that the government's investment in the facility be reassessed.

Michael Cherry

\section{UN agency launches biotech data network}

Vienna. The United Nations Industrial Development Organization has introduced an online Biosafety Information Network and Advisory Service, which provides electronic access to a number of databases containing information about biotechnology guidelines, regulations and standards for the environmental release of genetically-modified organisms.

The network provides details on national regulatory authorities worldwide, as well as an electronic gateway to other biosafetyrelated databanks. A key function will be to help national authorities draw up and implement biosafety guidelines, and the network is also intended to provide industry with information on worldwide regulatory trends. 